\title{
Cytological Studies on Host-parasite Relations in Experimental Leprosy of Mice
}

\author{
Tsutomu Watanuki and Katsuhiro Nakamura \\ The Second Department of Pathology (Prof. Emeritus \\ K. Akazaki and Prof. N. Sasano), \\ Tohoku University School of Medicine, Sendai \\ Sadao Takase and Nobuhiko Takahashi \\ The Second Department of Internal Medicine (Prof. T. Torikai), \\ Tohoku University School of Medicine, Sendai
}

\begin{abstract}
The details of different manifestation patterns of experimental leprous lesions of mice were described from the viewpoint of host $v s$. parasite relationship and the reticuloendothelial origin of the lepra cell. Three kinds of pretreatment, i.e., typhoid vaccine as a stimulant, Evans blue as a disturbant and cardiolipin as a depressant of the reticuloendothelial function were given to mice of dd-strain before the inoculation of lepra bacilli of Hawaiian strain. The experiments were carried out up to 15 weeks of the infection. The results obtained by histological, hematocytological, electronmicroscopic and enzymohistochemical methods were as follows:

1) The manifestation types of leprous lesion were significantly influenced by functional activity of the reticuloendothelial system of the host.

2) Lepra cells developed from the histiocyte and its precursor, the prehistiocyte, in the loose connective tissue proper.

3) The functional maturity of histiocytes as indicated by the digestion activity on the bacilli determined whether the involved cells were transformed into the lepra cell or not.
\end{abstract}

It is needless to say that the mesenchyma, particularly the reticuloendothelial system (RES), plays the most important role in inflammation as a defensive mechanism of the host. In this respect, a series of our studies ${ }^{1,2}$ on the RES have been carried out for an exact evaluation of inflammation from the viewpoint of host vs. parasite relationship. In one of them, three different types of manifestation of experimental mouse leprosy were induced by changing reticuloendothelial activities. Namely, the lesion of tuberculoid type was induced when the reticuloendothelial function was stimulated by typhoid vaccine pretreatment, lepromatous type by slight depression of the system with cardiolipin pretreatment and the type of diffuse exudation associated with partial necrosis by inhibition with Evans blue pretreatment, respectively. ${ }^{2}$

Received for publication, September 1, 1967. 
In the present paper, the authors will describe the process of different manifestations of the disease and demonstrate the reticuloendothelial origin of lepra cells by several cytological methods.

\section{Materials and Methods}

Three hundred and twelve male albino mice of dd-strain, 8 to 9 weeks of age, were used. The materials for pretreatment were administrated intraperitoneally each $0.1 \mathrm{ml}$ per $20 \mathrm{~g}$ of body weight of the mouse. The experimental animals were divided into 3 groups; Group A of typhoid vaccine injection for once, Group B of $0.5 \%$ aqueous solution of Evans blue given five times every other day, and Group $\mathrm{C}$ of $0.05 \%$ saline emulsion of cardiolipin fifteen times every other day. Sixteen days after typhoid vaccine injection in Group $A$, and 10 days after the first injection of Evans blue in Group $B$ and 30 days after the first injection of cardiolipin in Group $\mathrm{C}$, living murine lepra bacilli $\left(10^{-2} / 0.2 \mathrm{ml}\right.$, Hawaiian strain) were inoculated into the subcutaneous tissue of the back of mice. The animals were kept under observation up to 15 weeks of the inoculation.

Subcutaneous connective tissues of the back in the region of inoculation were examined and those of the anterior abdominal wall were used as controls. The tissue specimens were stretched on a slide glass, dried quickly and stained usually with the May-Grünwald-Giemsa solution. A part of the specimens was supravitally stained with neutral red and Janus green B and were observed alternately by the routine light microscope and the phase contrast microscope.

Methods of enzymohistochemistry applied were those for cytochrome oxidase (Gräff), succinic dehydrogenase (Wachstein-Meisel), alkaline phosphatase (Hino), acid phosphatase (Gomori), ATP-ase (Gomori), non-specific esterase (Braunstein), lipase (Gomori), beta-glucuronidase (Fischman-Baker), leucine aminopeptidase (Burstone-Nachlas) and phospholylase (Takeuchi).

The material for electron microscopy was fixed in Caulfield's osmium tetroxide solution for 2 hours, dehydrated in graded acetone and embedded in methacrylate. Ultra-thin sections were stained with saturated uranyl acetate or phosphotungstic acid and observed with a Hitachi HU-10 type electron microscope.

\section{Results}

\section{A) Typhoid vaccine pretreated (TV) group}

On the 17th day of typhoid vaccine administration, histiocytes in the subcutaneous connective tissue were found increased in number, occasionally making a conglomerate, together with appearance of their precursors, prehistiocytes, ${ }^{3}$ and their variants, small rounded histiocytes. ${ }^{3}$ Enzyme activities of the histiocyte, e.g., beta-glucuronidase, cytochrome oxidase and succinic dehydrogenase were much more intensive than those in animals having received cardiolipin or Evans blue. However, the histochemical activities of non-specific esterase and leucine aminopeptidase of prehistiocytes were less evident than in histiocytes. 
After the infection, many of histiocytes showed an active digestion of bacilli and recovered their original morphological characteristics. Meanwhile, certain histiocytic elements, particularly prehistiocytes of functional immaturity, were transformed into lepra cells without detectable digestion of bacilli.

At the 10th week of the infection, circumscribed granulomas became palpable in the majority of animals in the subcutaneous layer of the area of inoculation.

Microscopically, they showed leprous granuloma of tuberculoid type, which consisted mainly of epithelioid cells with an occasional mixture of a small number of lepra cells. Other inflammatory cells, e.g., multinucleated giant cells, lymphoid cells or plasmacytoid cells, were infrequently found.

The digested bacilli in the histiocyte, which became stainable with neutral red, appeared at first around the nucleus. Afterwards, they were distributed throughout the cytoplasm and fused into the neutral red granules which increased markedly in number in later stages of the disease. Consequently, well preserved bacilli were scarcely seen within the cell and in the intercellular tissue space.

Electronmicroscopically, the bacilli were mainly observed in the agranular endoplasmic reticulum which were formed by invagination of the cell membrane (Fig. 1). It was characteristic of TV group that primary lysosomes of the histiocyte became enlarged and extremely abundant (Fig. 2).

The acid phosphatase (AcPase) activity in the histiocyte was moderately or markedly reduced immediately after ingestion of bacilli, but increased thereafter progressively until the bacilli were completely digested. The activities of lipase and nonspecific esterase in the histiocytes were lowered in earlier stages of phagocytosis, but temporarily showed a progressive increase with digesting process (Fig. 5). In later stages, however, they decreased to the normal level. Similar but less evident activities were confirmed of beta-glucuronidase and aminopeptidase of histiocytes.

\section{B) Cardiolipin pretreated (CL) group}

After the administration of cardiolipin, subcutaneous histiocytes slightly decreased in number and the histochemical activities of AcPase, beta-glucuronidase, non-specific esterase and lipase were less conspicuous than in cases of typhoid vaccine administration.

Leprous nodules became palpable approximately in $30 \%$ of the animals by the end of the 7 th week of infection. Histologically, they were typical lepromatous foci, which consisted mainly of lepra cells. In or around the lesions the histiocyte of fixed type, epithelioid cells and lymphoid cells were observed but less frequently than in TV group.

The typical lepra cells were large in size and oval or round in shape. Their cytoplasms were filled with multiplying bacilli, and consequently their nuclei were located eccentrically. In our observation, lepra cells developed less frequently from histiocytes than from their precursors, prehistiocytes (Fig. 3). Moreover, 
prehistiocytes and even a majority of histiocytes in this group showed little digestion of the bacilli and rather allowed their active multiplication in the cytoplasm.

When the bacilli became predominant in the cytoplasm, mitochondria, supravitally stainable with Janus green B, and neutral red granules were significantly reduced in number.

Electronmicroscopically, the fundamental process of phagocytosis was the same as observed in TV group. However, the agranular reticulum and lysosomes were few in histiocytes. The digestion of the bacilli in phagocytic granules was also less active than in TV group. There were also prehistiocytes containing bacilli in the cytoplasm sometimes without enclosing limiting membrane.

It was remarkable that the activities of cytochrome oxidase and succinic dehydrogenase in lepra cells were histochemically markedly reduced, while no remarkable changes were observed in the histiocytes not containing the bacilli.

\section{C) Evans blue pretreated (EB) group}

Subcutaneous histiocytes were markedly decreased in number and became degenerated after Evans blue injection even at the time of the inoculation of the bacilli. The activities of the histochemically investigated enzymes in histiocytes were markedly reduced.

Within a week of the inoculation, many of the animals died of bacillemia. The incidence of palpable nodules was low. However, slightly soft swelling of considerable extension in the subcutaneous tissue was observed in certain instances approximately 8 weeks after the inoculation of bacilli.

Histologically, diffusely exudative and partly necrotic changes were characteristic of this group. The bacilli had hardly been digested in the cytoplasm. They were observed within Evans blue granules of the histiocyte in occasional instances. Such histiocytes of lower phagocytic activities were apt to be destroyed without being transformed into lepra cells, while complete digestion

TABLE 1. Cell components in three patterns of experimental leprosy

\begin{tabular}{|c|c|c|c|c|c|}
\hline \multirow{2}{*}{ Pretreatment } & \multirow{2}{*}{$\begin{array}{l}\text { Lesions of } \\
\text { leprous foci }\end{array}$} & \multirow{2}{*}{$\begin{array}{l}\text { Inflammatory } \\
\text { cell reaction, } \\
\text { particularly of } \\
\text { histiocytes }\end{array}$} & \multirow{2}{*}{$\begin{array}{l}\text { Predominant } \\
\text { cell pattern in } \\
\text { leprous foci }\end{array}$} & \multicolumn{2}{|c|}{ Location of bacilli } \\
\hline & & & & Histiocyte & Tissue space \\
\hline Typhoid vaccine & $\begin{array}{c}\text { Tuberculoid } \\
\text { type }\end{array}$ & Ht & $\begin{array}{l}\text { Epithelioid cells } \\
\text { or histiocytes } \\
\text { (occasionally } \\
\text { with active } \\
\text { digestion of } \\
\text { bacilli) }\end{array}$ & $-\sim+$ & + \\
\hline Cardiolipin & $\begin{array}{l}\text { Lepromatous } \\
\text { type }\end{array}$ & $\perp$ & $\begin{array}{l}\text { Lepra cells (with } \\
\text { multiplying } \\
\text { bacilli) }\end{array}$ & H & $H$ \\
\hline Evans blne & $\begin{array}{l}\text { Diffuse exuda- } \\
\text { tive, partly } \\
\text { necrotic change }\end{array}$ & $\pm \sim-$ & $\begin{array}{l}\text { Degenerated } \\
\text { histiocytes }\end{array}$ & + & H \\
\hline
\end{tabular}


TABLE 2. Cytological and histochemical patterns of histiocytes in the leprous foci

\begin{tabular}{|c|c|c|c|c|c|}
\hline \multirow[b]{2}{*}{ Methods } & \multirow[b]{2}{*}{ Findings } & \multicolumn{4}{|c|}{ Histiocyte } \\
\hline & & Fixed type & $\begin{array}{l}\text { With multiply- } \\
\text { ing bacilli (lepra } \\
\text { cell) }\end{array}$ & $\begin{array}{c}\text { With digested } \\
\text { bacilli }\end{array}$ & $\begin{array}{l}\text { Degen: } \\
\text { erated }\end{array}$ \\
\hline \multirow{2}{*}{$\begin{array}{c}\text { Supravital } \\
\text { staining }\end{array}$} & $\begin{array}{c}\text { Neutral red } \\
\text { granules }\end{array}$ & H & - & + & - \\
\hline & Mitochondria & $\begin{array}{c}+ \\
\text { (Granular) }\end{array}$ & $\cdots \sim \pm$ & + & $\pm \sim-$ \\
\hline \multirow{9}{*}{$\begin{array}{l}\text { Enzymohisto- } \\
\text { chemistry }\end{array}$} & $\begin{array}{l}\text { Cytochrome } \\
\text { oxidase }\end{array}$ & $H$ & $-\sim 1$ & $\perp \sim H$ & $-\sim+$ \\
\hline & $\begin{array}{l}\text { Succinic } \\
\text { dehydrogenase }\end{array}$ & H & $-\sim \perp$ & $1 \sim+$ & $-\sim+$ \\
\hline & $\begin{array}{l}\text { Alkaline } \\
\text { phosphatase }\end{array}$ & - & - & $\perp \sim+$ & - \\
\hline & $\begin{array}{l}\text { Acid } \\
\text { phosphatase }\end{array}$ & $H 1$ & \lrcorner$\sim+$ & $+\perp \sim H$ & $-\sim+$ \\
\hline & ATP-ase & 井 & $\pm \sim 1$ & $+\sim H$ & $-\sim+$ \\
\hline & $\begin{array}{l}\text { Non-specific } \\
\text { esterase }\end{array}$ & $H$ & $+\sim H$ & H & $-\sim+$ \\
\hline & Lipase & H & + & H & $-\sim+$ \\
\hline & $\begin{array}{l}\beta \text {-Glucuro- } \\
\text { nidase }\end{array}$ & $H$ & $\operatorname{tr} t$ & $+\sim H$ & $\sim+$ \\
\hline & $\begin{array}{l}\text { Amino- } \\
\text { peptidase }\end{array}$ & $H$ & $t$ & $t-H$ & $-\sim+$ \\
\hline \multirow{3}{*}{$\begin{array}{l}\text { Electron } \\
\text { microscopy }\end{array}$} & Mitochondria & $H$ & \pm & + & \pm \\
\hline & $\begin{array}{l}\text { Specific } \\
\text { granules } \\
\text { (= primary } \\
\text { lysosome) }\end{array}$ & H & \pm & + & \pm \\
\hline & $\begin{array}{l}\text { Agranular } \\
\text { endoplasmic } \\
\text { reticulum }\end{array}$ & + & \pm & + & \pm \\
\hline
\end{tabular}

of the bacilli did not take place. Finally, the bacilli were cast into the tissue space.

Electronmicroscopic investigations of the histiocyte revealed that the mitochondria were swollen to round ones with disarranged cristae. Granular reticulums of elongated type were sometimes found with remarkably decreased ribosomes.

Histochemical enzyme activities in histiocytes were markedly reduced (Fig. 7).

\section{Discussion}

The strong phagocytic ability of the RES was correlated with high histochemical activities of several enzymes, particularly of AcPase and non-specific 
esterase etc. ${ }^{4-6}$ and with the electron microscopic finding of abundant intracellular organelles such as agranular endoplasmic reticulum, phagocytic granules and lysosomes. ${ }^{6}, 7$ Typhoid vaccine accelerates the phagocytic activity of RES and induces a marked proliferation of subcutaneous histiocytes, Kupffer's stellate cells of the liver and so on, with patterns of enhanced histochemical enzyme activities and increased ultrastructural cell organelles. The opposite findings have been known to develop if the prednisolone is adequately administrated. ${ }^{8}$

In order to vary the functional activity of RES, the present authors used cardiolipin as a depressant and Evans blue as a disturbant after the manner of our previous experiment. ${ }^{2}$ Three different manifestation types of leprous changes were induced in the experimental animals with different pretreatments. The phagocytic activity or digestive process of the bacilli in the subcutaneous histiocytes also varied considerably according to the manifestation types. It was most remarkable in TV group.

At the early stage when the bacilli were engulfed in the agranular endoplasmic reticulum, the peribacillary space described by Allen et al. ${ }^{8}$ and Leake and Myravik ${ }^{9}$ was occasionally observed, and histochemical activities of lysosomal enzymes of histiocytes showed a temporary reduction. Leake and Myravik further described that an intense activity of AcPase was evidently demonstrated in the peribacillary body at the stage of progressing digestion. Therefore, it is reasonable to assume that the peribacillary body would develop somewhat later in the course of digestive process.

With the progressive digestion of bacilli, the neutral red granules increased in number, corresponding to abundant primary lysosomes which occasionally reached nearly $1 \mu$ in diameter. These findings, however, were hardly seen in prehistiocytes which exhibited only weak histochemical reactions for non-specific esterase and leucine aminopeptidase. The insufficiency of these enzyme activities in the digestion of the bacilli seemed to contribute to transforming prehistiocytes into lepra cells. When the bacilli within the clasmatotic fragments of histiocytes were again ingested by other cells, they seemed to be more easily digestible than when they were initially ingested (Fig. 4).

It is also interesting that the activities of cytochrome oxidase and succinic dehydrogenase were found sometimes slightly depressed even in actively functioning histiocytes. This phenomenon, however, would indicate a functional deviation rather than a real functional suppression of the cells on account of a possible formation of NADH and NADPH in mitochondria independent of the cytochrome system, for example, probably via the hexose-phosphate pathway. That is, it may be an expression of the bipolar activity of the mitochondria.11

Cardiolipin administration slightly increased the number of prehistiocytes and stimulated their cellular activities but the effects were much less evident than those of typhoid vaccine. Both histiocytes and prehistiocytes showed a marked depression in their histochemical activities of cytochrome oxidase and succinic dehydrogenase and a distinct decrease in the number of intracellular 
organelles, e.g., agranular endoplasmic reticulum of small size, mitochondria and others as well. Such cells were likely to be easily transformable into lepra cells.

Actually, lepra cells were prevalent in the CL group. Cardiolipin is a wellknown component of the murine lepra bacillus and it suppresses slightly the reticuloendothelial function and the activity of the bacillus as described before. The development of lepra cells from histiocytes depend on the maturity of the latter cells.

\section{Acknowledgment}

We are greatly indebted to Prof. M. Kojima, the First Department of Pathology of the Fukushima Medical College for his guidance throughout the study.

\section{References}

1) Kojima, M., Takagaki, M., Watanuki, T., Ogata, M., Kuroda, M. \& Ohta, S. Cytological studies on inflammation, especially with reference to the origin of socalled round cells in inflammatory foci. Tohoku J. exp. Med., 1958, 69, 207-224.

2) Akazaki, K., Kojima, M., Miyakawa, K., Watanuki, T., Hayashi, T. \& Nakamura, K. Experimental studies on the functional condition of reticuloendothelial system, especially with reference to the various manifestation types of the leprous and tuberculoid foci. Tohoku J. exp. Med., 1959, 70, 325-334.

3) Hosoda, S. Enzymohistochemical studies on various transformations of the subcutaneous histiocyte. Tr. Soc. Path. Jap. (Jap.), 1961, 50, 23-52.

4) Takase, S. Enzymohistochemical studies of peritoneal macrophages of mice. Acta haem. jap. (Jap.), 1965, 28, 130-184.

5) Nakamura, K. \& Watanabe, I. Electron microscopy of acid phosphatase activities in subcutaneous connective tissue cells of rabbit. Tohoku J. exp. Med., 1965, 86, 230237.

6) Sato, E. Electron microscopy on the subcutaneous histiocyte of rabbit. Proc. Jap. Soc. R.E.S. (Jap.), 1965, 5, 213-236.

7) Watanuki, T., Nakamura, K., Namiki, T., Sato, E., Sugawara, S., Sakai, H., Takahashi, N., Fukuda, T., Watanabe, I. \& Kumagai, S. Morphological manifestations of reticuloendothelial function. Relationship between carbon black clearance and morphological changes of the reticuloendothelial cells. Tohoku J. exp. Med., 1962, 79, $85-101$.

8) Allen, J.R., Brieger, E.M. \& Rees, R.J.W. Electron microseopy of the host-cell parasite relation in murine leprosy. J. Path. Bact., 1965, 89, 301-306.

9) Leake, E.S. \& Myrvik, Q.N. Digestive vacuole formation on alveolar macrophages after phagocytosis of mycobacterium smegmatis in vivo. J. Reticuloendothel. Soc., $1966,3,83-100$.

10) Takahashi, N. Enzymohistochemical studies on the hepatic reticuloendothelial cells. Proc. Jap. Soc. R.E.S. (Jap.), 1966, 6, 262-271. 


\section{Legends for Figures}

Fig. 1. The lepra bacilli which have been taken into the histiocyte through the process of invagination are found in the agranular endoplasmic reticulum. TV group, 2 weeks after the inoculation of lepra bacilli. $\times 10,000$.

Fig. 2. Large primary lysosomes are distinct in the cytoplasm of a histiocyte when the animal was treated with typhoid vaccine. Five weeks after the infection. $\times 35,000$. 


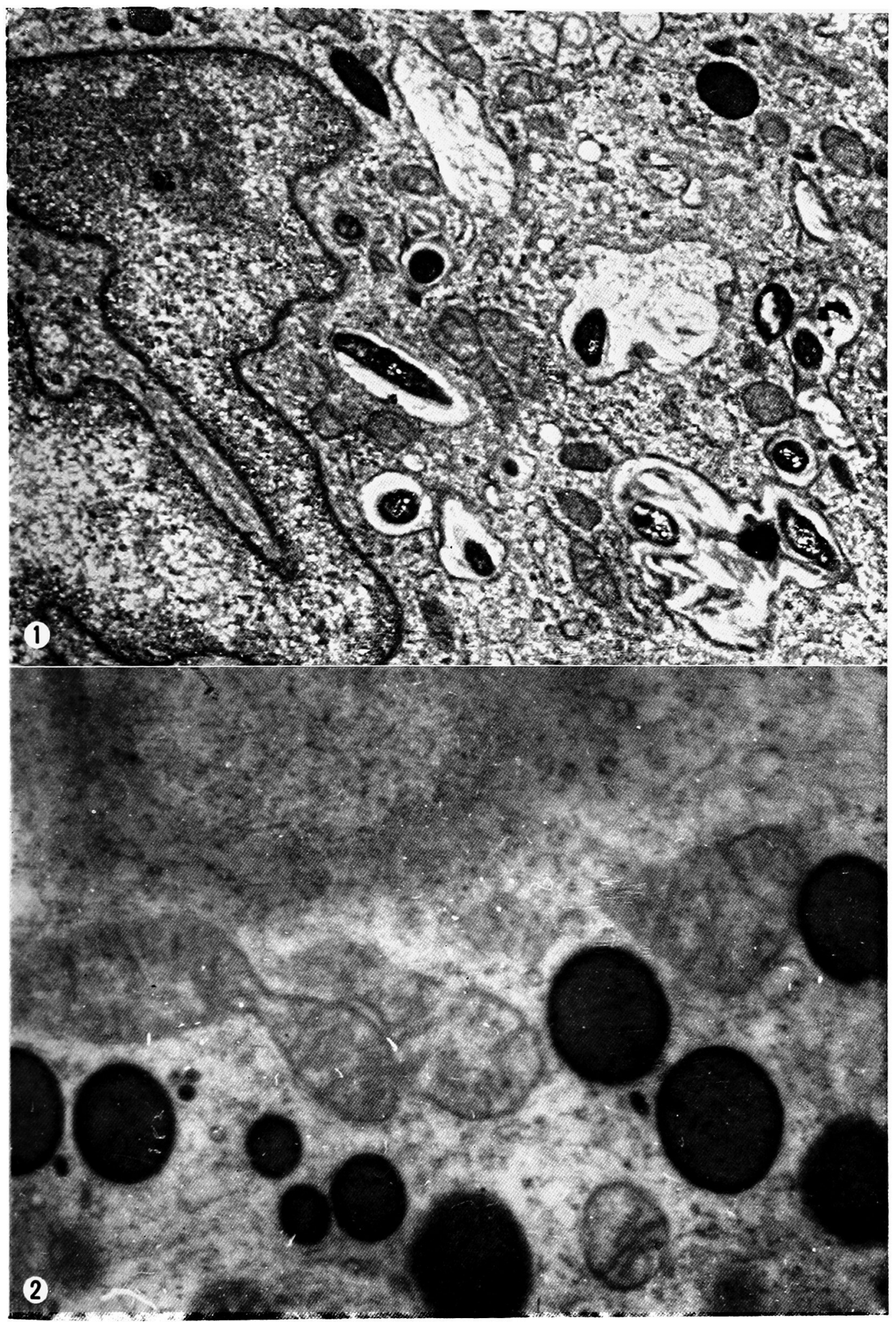


Fig. 3. A bacillus is entrapped in the cytoplasm of a prehistiocyte. There are numerous agranular endoplasmic reticula but a few lysosomes in the cytoplasm. Such a prehistiocyte is later transformed into the lepra cell. CL group, 10 weeks after the infection.

Fig. 4. Plasmatocytic cytoplasms containing bacilli are again phagocytised with a histiocyte. In this case, the digestion of the bacilli seems to progress more easily than in primary phagocytosis. CL group, 8 weeks after the infection. $\times 55,000$. 


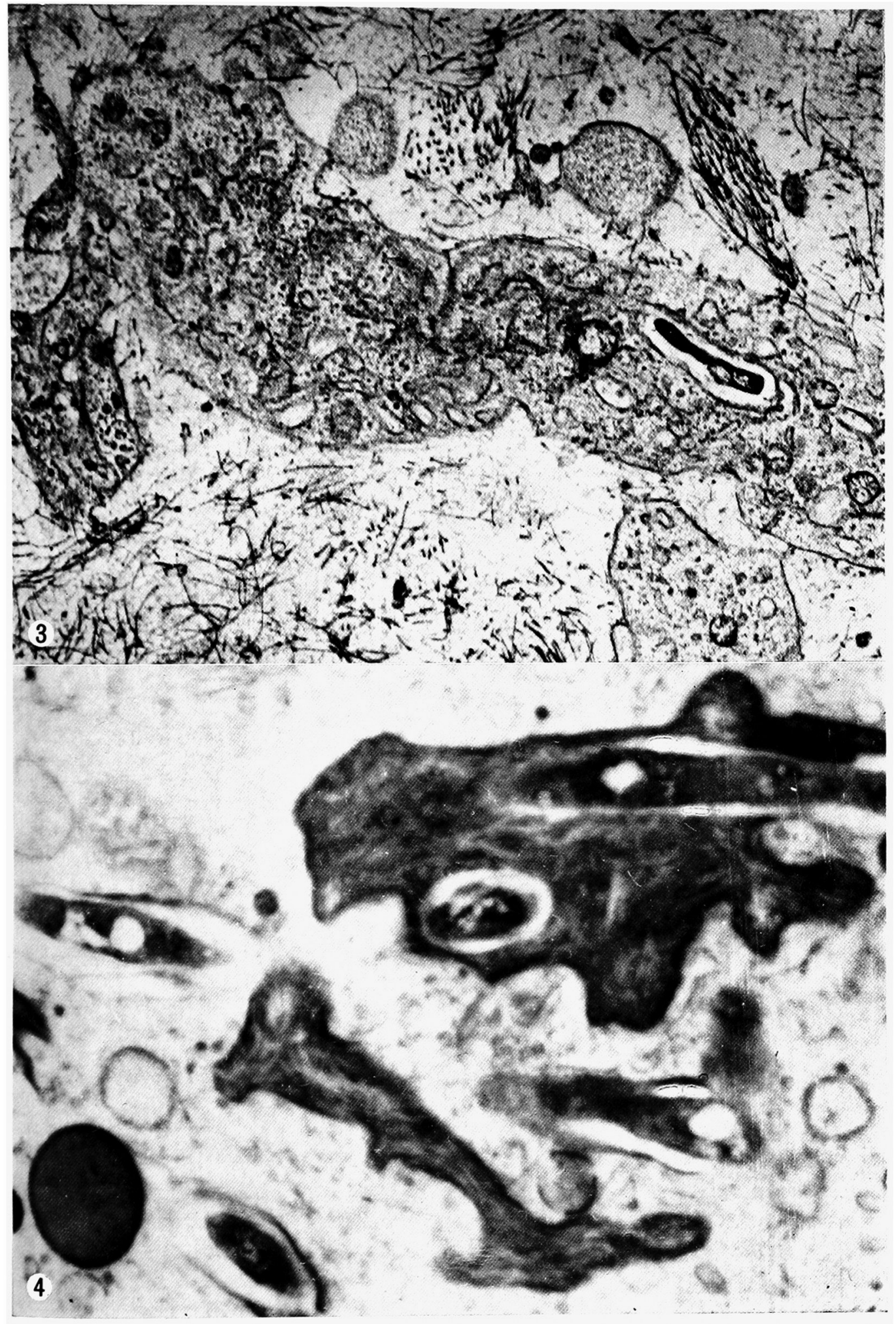


Figs. 5-7. The esterase reaction of histiocytes, 10 weeks after the inoculation of lepra bacilli. $\times 1,000$.

Fig. 5. In the histiocytes activated by typhoid vaccine, enzymohistochemical activity of non-specific esterase is accelerated as the process preceding the digestive degeneration of the bacilli.

Fig. 6. The esterase activity of lepra cells is slightly suppresssed on account of depressed right upper portion showed a significant acceleration of esterase activity after the digestion of bacilli.

Fig. 7. The esterase activity of lepra cells is distinctly suppressed, the functions of histiocytes being affected by Evans blue. 


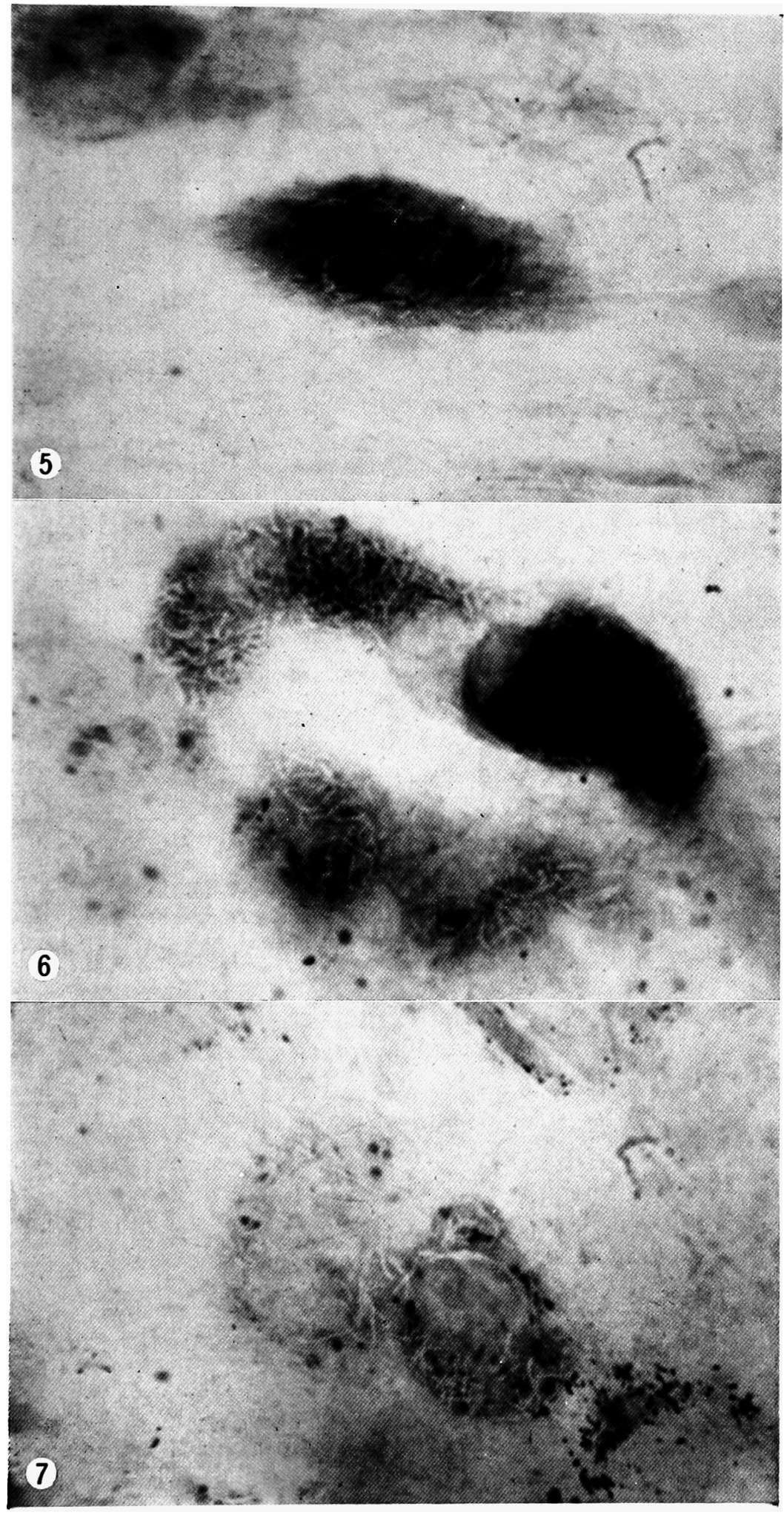

